sulphamerazine, sulphamezathine, sulphadiazine and sulphathiazole. As for persistence, as measured by the presence of sulphonamide in the aqueous 7 hours after administration, sulphamerazine gave the highest value with successively decreasing values for sulphamezathine, sulphanilamide, sulphadiazine and sulphathiazole. Assessment of the highest aqueous level as a percentage of the highest plasma level showed the highest value for sulphanilamide, with successively lower values for sulphamerazine, sulphadiazine, sulphamezathine and sulphathiazole.

3 . In the rabbit the highest concentration in the aqueous was given by sulphadiazine, with successively lower values for sulphamezathine and sulphamerazine. Sulphadiazine also proved to be the most persistent as assessed by the aqueous concentration at 3 hours. The highest aqueous/plasma ratio was shown by sulphamezathine.

I am greatly indebted to Dr. A. Spinks, of the Research Laboratories. Imperial Chemical Industries Ltd., Manchester, for assistance in carrying out the experiments.

\title{
REFERENCES
}

Bellows and ChinN (1939).-J. Amer. Med. Assoc., 112, 2023.

(1941).-Arch. of Ophthal., 25, 294.

LIEBMAN and NEWMAN (1941).-Arch. of Ophthal., 26, 472.

MEYER, BLOCH and CHAMBERLAIN (1941).-Amer. J. Ophthal., 24, 60.

PINKOFF (1939). -Ophthalmologica, 97, 357.

SCHEIE and SOUDERS (1941).-Arch. of Ophthal., 25, 1025.

\section{THE SIGNIFICANCE OF OCULAR COMPLICATIONS FOLLOWING VACCINATION*}

BY

\section{EMANUEL ROSEN}

NEWARK, N.J.

THE occurrence of ocular complications shortly after vaccination, of the secondary or indirect variety, is not new, for it has been reported in ophthalmic literature about twelve times. The observation of a greater number of cases in a period of two months would indicate that these complications should provoke greater interest than they have hitherto received. This secondary type of ocular complication is so named in order to differentiate the accidental vaccinial inoculation produced by first scratching the

\footnotetext{
* Received.for publication, August 14, 1948.
} 
pustule and then touching the eyelid, from the ocular complication which is endogenous and usually part of a post-vaccinial encephalitic phenomenon.

While at Fort Benning, Georgia, in 1945, I observed an interesting case of interstitial keratitis associated with vestibuloauditory symptoms following vaccinia. This case was similar to four cases reported by David Cogan ${ }^{4}$, which introduced a new syndrome of unknown aetiology, namely, non-syphilitic interstitial keratitis associated with vestibulo-auditory symptoms. After studying these cases it appeared that our case was one of the same syndrome, save that the patient's symptoms developed seven days after vaccination. It seemed that this 'syndrome might be a variety of post-vaccinial encephalitis, since both the fifth and eighth cranial nerves were involved. The syndrome was bilateral, recurrent and reversible. The case report in some detail is as follows :-

The patient was a 30-year-old male who had served in the armed forces for over four years. The onset of acute illness occurred on March 13, 1945, one hour after the noonday meal. The initial symptom was nausea which was followed shortly by retching and then by projectile vomiting. After vomiting had ceased the patient noticed a persistent dull nuchal headache which did not keep him from his work that afternoon, throughout which it remained unchanged. There were no chills, dizziness or fever at this time. The patient slept well that night, but on awakening the next morning he felt dizzy, as though the bed were rotating. This sensation vanished in a few hours, so that he was able to report to work at the usual time. Again, following a frugal noonday meal, the symptoms of the previous day returned, together with an oppressive tightness about the neck. The dizziness recurred, and he returned home, where he spent a comfortable night. On this second day the headache did not recur. When he got up on March 15, the patient was still dizzy and somewhat faint. He was admitted by ambulance to the hospital, where followed a mild bout of retching. The only symptom for the first week was persistent dizziness, more pronounced when the patient stood up. At no time was the temperature abnormal. His past history indicates that the patient has had several mild virus diseases, including several slight attacks of herpes labialis. Mumps, measles, scarlet fever and chicken-pox were all contracted without any serious sequelae. On March 6 the patient was vaccinated with vaccinia virus, and was also given a stimulating dose of triple typhoid. There was no systemic or local reaction to the vaccination or to the typhoid injection, and the incident had been forgotten.

On admission the physical examination was reported as normal. The temperature was $98^{\circ}$, the blood pressure was $114 / 86$, and the pulse rate was 86 . There were no neurological signs and no physical findings other than vertigo. The urine examination was negative. A blood count performed upon the day of admission showed a leucocytic count of 11,700 of which 72 per cent. were "polymorphs" and 28 per cent. "lymphocytes." Several subsequent blood counts were performed with an 8,000 to 15,000 leucocytic variation, and maintenance of the above percentage for the differential count. Routine tests for syphilis, undulant fever and tularemia were reported as being negative. Spinal fluid studies were made ten days after the onset of the illness, and were reported as normal. $\mathrm{X}$-rays of both the skull and the chest were negative. Because of the persistence of vertigo without associated symptoms further consultation was sought along otological and neuropsychiatric lines. The neurological examination was -negative. The psychiatric examination is summarized in the following paragraph:- "This officer appears to be a passive neurasthenic individual. In the service he failed to gain a commission because of lack of physical performance and leadership of men 
in a combat type of duty. He was given a form of work following this failure which was technically and psychologically very acceptable to him. As a result of his work he gained a warrant officer's status which to him was very gratifying. While on leave, he was, without previously being informed, relieved of his command and placed upon an "available" list. He took this in a normal manner consciously, and reacted with "well a soldier is never put." Psychologically, however, this was a serious failure upon his part. With this news there was the threat of combat theatre duty and separation from his wife, upon whom he depended a great deal emotionally. He reacted to the situation in the only manner he is capable of, namely, an acute episode of hysteria. His neurasthenic features have existed for many years and manifested themselves early in his military career. Diagnosis :- psychoneurosis and neurasthenia.

Ear, nose and throat studies were of indeterminate value. Upon rechecking the history it was learned that two years earlier the patient had noticed buzzing in his ears shortly after swimming. This buzzing had only lasted two days. One week after the onset of acute vertigo the patient complained of transient auditory disturbances. He described two distinct kinds: one was of the "cockleshell" variety; the other resembled the hum of an undialled telephone. The otologist reported that the results of his audiometric and labyrinthine studies were unreliable, transitory, indeterminate and contrary to expectation. During the second week the transient auditory symptoms appeared. Ocular manifestations arose about the first of April, being quite mild at the onset. The right eye was first involved. There was no pain and no secretion. There was a mild conjunctival injection and a slight sensitivity to light. After instillation of a mild astringent (zinc sulph. $\frac{1}{2}$ per cent.) the eye appeared to improve, and remained comfortable for about ten days, after which time similar but more severe symptons recurred. Examination at this time disclosed slight aqueous flare, thickening of the cornea, several folds in Descemet's membrane, and many "craters" visible in the zone of specular reflection. There were also several small foci of opacification in the corneal stroma. At various places the limbal vessels were beginning to push into the corneal substance superficially. Under atropine drops locally, and typhoid therapy intravenously, the right eye gradually cleared in about three weeks, but by this time a similar picture had begun to develop in the left eye. Attacks continued to shift from one eye to the other, each attack lasting about one week, and then clearing without any residuum. The attacks were unrelated to any systemic manifestation. The events leading up to the patient's hospitalization, along with the neuropsychiatric findings and the presence of conjunctival secretion, even when a definite keratitis existed, aroused the suspicion of malingering. The patient was kept under observation, and there was a gradual improvement over many months. In this period there were several recurrences, but eventually all ocular and otologic symptoms subsided.

From this case report it seemed apparent that since ophthalmology deals with fifty per cent. of the cranial nerves, and since post-vaccinal encephalitis is a cranial nerve involvement, the ophthalmologist should be in an excellent position to see cases of post-vaccinial encephalitis at an early stage. Looking upon the eye as a bud from the brain, in whose interior one can deduce events occurring in the brain, particularly as regards vascular structures, it seems that there is further evidence of this ocular localization in complications of post-vaccinial encephalitis. The ophthalmologist may well detect certain vascular phenomena in the eye-for example, in the avascular cornea-and thus solve the problem which for so many years has eluded the clinical investigator seeking to explain the aetiology of post-vaccinial encephalitis. Changes in the optic nerve-head from pressure disturbances, inflammation and congestion, are not the only possibility. Direct 
observation of the blood-vessels may be of value when the blood itself is altered, and the importance of the avascular cornea for observation of allergic phenomena cannot be over-emphasized, as shown by the work of Rich and Folis, $1940^{\circ}$, whose studies of allergic phenomena in such tissues led them to believe that sensitization is due to the capillaries at the corneal limbus, not to corneal tissue per se. In animals previously sensitized, serum injected into the cornea produced inflammatory changes at the limbus. If, however, one eye had an artificially vascularized cornea, serum introduced into the cornea of a sensitized animal produced a haemorrhagic area within the corneal stroma itself at the terminus of this acquired vascularization.

A second case which we observed has a bearing upon the experiments of Rich and Folis.

Mr. J.K., age 37 years, was first seen at Camp Lee, Virginia, in the Fall of 1944 because of a severe metaherpetic keratitis in the left eye. This was his third attack. The lesions responded to treatment very slowly, requiring ten weeks of hospitalization before any permanent improvement was effected. Then he was discharged, and returned to duty. He remained free from eye symptoms until two weeks after vaccination in May, 1947, when the left eye became inflamed and painful. Examination revealed an inflamed cornea which was at least doubled in thickness. There was a general greyness over most of the corneal surface. The conjunctiva was intensely injected. There were many folds in Descemet's membrane. The optical section under the narrow beam looked very like a section through a washboard. One vessel ran deeply into the substance of the cornea, starting at nine o'clock. At first the activity seemed limited to the corneal substance just beyond this new vessel. During the acute period the iris could not be seen. Within the substance of the cornea there were several small infiltrates spindleshaped in cross section. The acute.process continued for several weeks, and gradually subsided.

A review of the literature on post-vaccinial encephalitis indicates that the allergic theory cannot be lightly dismissed. Putnam ${ }^{21}$; Finley $^{7}$, Davidoff 5 , Flexner ${ }^{8}$, Glanzmann ${ }^{12}$ and others believe that post-vaccinial encephalitis is an allergic response, whose incubation period is definitely related to the exanthem. The incubation period may be accelerated, and has been shown to be so in cases of revaccination. The symptoms of post-vaccinial encephalitis usually appear on the eleventh day, but in revaccination they may arise as early as the seventh day. I believe that this incubation period or interval following inoculation is more important than the symptomatology greatly stressed in so many writings. The fact that the patient develops coma, diplopia, nausea, headache, etc., is not nearly so important as the fact that these symptoms appear seven, eight, nine, ten or eleven days after vaccination. Therein lies the most important single finding in a variegated disease which for years has been so baffling.

A review of every autopsy available, both of post-vaccinial encephalitis and of the post-exanthematous encephalitides, made it 
clear that one was dealing with the same pathological entitywhether of post-measles, post-pertussis, post-influenzal or the other virus diseases common in childhood. It is not difficult to understand why, for so many years, this problem has been a baffling one. The neuropathological picture in any of these diseases cannot be differentiated by the most competent investigator. On the other hand, when one considers the difficulties encountered in diverse staining techniques of nerve tissue, one can understand the variation in the reports of pathological studies concerning this group of diseases. One striking aspect revealed by this review of post-vaccinial encephalitis is the close relationship between the exanthematous encephalitides and acute multiple sclerosis. There are several ocular observations in support of this relationship. Thus Von Herrenschwand in $1939^{24}$ wrote about ocular complications in post-vaccinial encephalitis. In 1912 he had reported a case of a six-year-old child who developed a post-vaccinial bilateral sixth nerve palsy. In his second report (1939) he listed three new cases, each of which came to autopsy. The patients were all about eight years old. Encephalitis occurred seven to ten days after vaccination, and death followed in two to three weeks. Clinical eye studies were not recorded in these cases, but autopsies including sections of the eye were performed with interesting results. In the first case there was an internal and external hydrocephalus with recent haemorrhage below the dura upon each side of the skull. Both trigeminal nerves and their sheaths were oedematous. The histological picture suggested an allergic response. A bilateral perineuritis of the optic nerve was present. The post mortem examination of the second case was most interesting as regards the ocular findings. The histopathological picture was an early retrobulbar neuritis, a condition which rarely comes to autopsy unless death ensues from some other cause. Von Herrenschwand believed that the presence of continuous circular lines of connective tissue within the vein was characteristic of post-vaccinial neuritis, and from this feature one could rule out other forms of encephalitis. Perhaps this concept of retrobulbar neuritis as determined by Von Herrenschwand's histopathological investigation in cases of post-yaccinial encephalitis; and the suggestion that we are dealing with an early allergic response may fit into the picture portrayed by Benedict ${ }^{2}$ in his studies upon retrobulbar neuritis. Certainly it is no coincidence that retrobulbar neuritis terminates as multiple sclerosis (Benedict ${ }^{2}$ ), and that multiple sclerosis resembles the post-vaccinial encephalitis histopathologically (Putnam ${ }^{21}$ ).

- Benedict's work seems further to be substantiated by Adler ${ }^{1}$, 
in whose series of 100 cases diagnosed as acute encephalitis of all varieties, fifteen per cent. eventually were recognized as multiple sclerosis because of the recurrence of attacks. Putnam has stated that certain types of encephalomyelitis represent the acute.stage of a process which we know in its chronic relapsing form as multiple sclerosis. The "sheathing", of retinal blood vessels described by Rucker"22, and the studies of Franklin and Brickner ${ }^{11}$ on vasospasm associated with multiple sclerosis appear to be two recent contributions to the study of multiple sclerosis which resemble similar pictures seen in the post-vaccinial ocular syndrome. There have been several cases observed following vaccination in which a process akin to "sheathing " has been seen in the fundus examination. An example of this type of ocular complication is the following: M.H., a 24-year-old male, was in apparently excellent health when he was re-vaccinated against smallpox. On awakening 21 days after vaccination he noted blurred vision more obtrusive in the right than in the left eye. Since he was unable to continue his clerical work, he consulted an ophthalmologist, who found the vision to be $20 / 50$ in the right eye and $20 / 40$ in the left eye. There was a mild bilateral macular oedema and a suggestion of general perivascular bifurcational constriction. The eye became worse in the next three days. Examined on the twenty-fourth post-vaccinial day, vision was 20/70 in each eye. At this time the macular oedema and perivascular sheathing were pronounced. Under vaso-dilators, atropine and rest there was gradual disappearance of the oedema, and return of vision to normal. Aetiological investigation revealed nothing abnormal. Franklin and Brickner in the abovementioned paper have referred to the recent work of Zeligs'28 in which macular oedema in young marines producing the characteristic "central serous retinopathy" is attributed to emotional tension with subsequent vasospasm. Franklin and Brickner state that "such tension has a profound and precipitating effect in cases of multiple sclerosis, as has been pointed out by several observers:". I have listed five cases of the above syndrome, each coming on within a definite period following vaccination. Two of these cases were reported before the New York Society for Clinical Ophthalmology in May of 1947 and are summarized herein :-

Case 1-(a) Mr. M.C., a 38-year-old radio mechanic considered himself to be in good health. He had had no physical ailments for several years. There was no history of allergy either immediate or remote, nor of vasoneurosis, nervous tension nor other features associated with vasospasm. The patient did not smoke. On awakening three days after being vaccinated, he observed in front of his left eye a spot which was more noticeable when he gazed upon a white background. 
Examination revealed a characteristic central serous retinopathic lesion. Physical examination including blood pressure studies were normal. The lesion cleared completely in three weeks. There was a central scotoma.

Case 2 (b) J.G., male jeweller aged 38 years, developed a spot before his left eye ten days after vaccination. The vision was only slightly impaired, so that he paid little attention to this impediment except when he attempted to use his jeweller's loupe. Then he found that he could not see an object unless he gazed at it eccentrically. When examined three weeks after vaccination, he was found to have a typical central serous retinitis, which cleared in three weeks. This patient had a mild hypertension. He has been under observation for the past twelve years and has hitherto never had any similar ocular condition.

The most dramatic cases in the post-vaccinial ocular syndrome are those of central serous retinopathy, for here the eye grounds reflect the process going on within the brain. Since postvaccinial encephalitis has been shown to be limited to the vascular structures, and since central serous retinopathy is a condition in which the tiny macular twigs are involved with passage of fluid into the macula, it seems that in this region one can obtain a clue to certain phenomena arising in the brain. Since this area is vulnerable, the patient too will early be aware of involvement.

The classification of multiple sclerosis within the demyelinating diseases, the vascular distribution, the recognition of an hyperallergic theory to account for the demyelinating diseases, and the unification of the pathology of the demyelinating diseases $\left(\right.$ Ferraro $\left.^{6}\right)$ would seem to express a further relationship between post-vaccinial encephalitis and multiple sclerosis. Another case which shows at least a questionable relationship to multiple sclerosis is the following: L.D., adult male age 39, was re-vaccinated in May, 1947. Ten days after vaccination he developed an unsteadiness and a slight swaying to his left side. On the fourteenth day a small central scotoma was present in the right eye. He was found also to have an acute labyrinthitis. Symptoms cleared rapidly in four weeks. Upon neurological consultation he was advised that he might be suffering from acute multiple sclerosis.

In a recent experimental study Morrison ${ }^{19}$ has produced encephalomyelitis in animals through the use of homologous. antigen. He has speculated upon the possibility of a lipoid antigen resulting from demyelination which could produce such conditions as multiple sclerosis and other demyelinating diseases. His studies substantiate the work of Putnam and of Ferraro, who have repeatedly maintained that the type of lesion one sees in the demyelinating diseases depends to some extent at least on the age of the pathological process. Morrison emphasizes the similarity which exists between the demyelinating diseases and the pathological picture in his experimental encephalomyelitis, which reaction is based upon an immunological response. 
Autopsy displayed definite arterial occlusion in some of the animals-a controversial point mentioned by Greenfield ${ }^{13}$ and Grinker $^{29}$. If medullation is of great importance in this immunological study, perhaps careful observation could be made upon patients who have medullated optic nerves visible ophthalmoscopically, and upon animals with a normal medullation in the fundi.

During the recent episode of mass vaccination in and about New York City, I observed many vaccinated patients and have had several physicians inform me of various complications following vaccination. There is no doubt that a great many symptoms which follow vaccination are "flare-ups" of dormant conditions. This apparent "light-up" of a so-called dormant condition was the most frequently observed of the ocular complications. Usually there was a healed choroidal lesion which appeared to spring into activity after vaccination. Variation in the onset of the symptoms can be explained by the location of the lesion, especially in respect of its proximity to the macula, and by the degree of exudation. The following cases exemplify this variety of ocular complication :-

Case 1-Miss P., age 23 years, was vaccinated on May 18 in routine fashion. On May 30 she noticed in front of her left eye several large opacities, which became much more pronounced in the bright sunlight, or when she looked at a white background. At first there was only a slight blur, but within three days vision was reduced to counting of fingers. The patient was admitted to the Newark Eye and Ear Infirmary, where all routine studies proved to be negative. These included Wassermann test, urine, Mantoux $(1: 1,000,000$ to $1: 10,000$ dilution), sinus studies and chest $X$-ray. Past history revealed chicken-pox, measles and whooping cough, all before the age of five years and all mild in character. There were no complications of these illnesses. The patient had never had any serious diseases and this hospitalization was her first. There was no family history of allergy and the patient had never had any indications of allergic reactions. She was first vaccinated at the age of one, with a normal response. Examination of this girl's eyes disclosed vision of fingers only in the left eye. The pupil was widely dilated; there were many large scattered precipitates on the back of the cornea. The vitreous contained many large greyish opacities, some globular in shape, others resembling large strands. These vitreous opacities were especially thick in the region of, or just anterior to, a large yellowish grey choroiditic patch about three disc-diameters in size. This exudate was quite recent, with edges still not healed and still non-pigmented. Although it was difficult to see through the turbid vitreous, particularly in this region, yet this lesion could be-seen just a little beyond an old upper nasal choroiditic patch heavily pigmented and completely healed. The disc appeared normal, although it could not be seen clearly.

Case 2-Mrs. R., age 29 years, was moderately myopic. She had had annual refractions by a well-known ophthalmologist in New York City. Vision had always been normal with her glasses. Physical examination performed after the birth of her second child and three months before the onset of her present eye complaint indicated that there were no abnormalities. About twenty days after an uneventful re-vaccination the patient complained of small spots in front of her left eye. These gradually became more pronounced, leading to further visual obscuration. In about three days the vision was reduced to fingers at four feet.

At the initial examination the left eye was seen to have a severe choroido-retinitis with many large and small corneal precipitates, a turbid vitreous and a large choroiditic patch of recent origin and extremely exudative, in the upper nasal 
quadrant. A small haemorrhage was adjacent. Near this new lesion were several smaller old, pigmented choroiditic patches all crowded along the path of the same blood-vessel. Under atropine, compresses, vaso-dilators and rest no appreciable improvement was noted in the next few weeks. The systemic investigation showed no aetiological factor, the following laboratory studies being reported upon as within normal limits: (1) Blood Count, (2) Blood sedimentation rate, (3) Blood chemistry, (4) Urinalysis, (5) Mantoux test 1:1,000 dilution, (6) Wassermann and Kahn, (7) X-ray of chest.

This group of cases illustrating a "light-up" of previously existing conditions need not necessarily be restricted to the eye. During the period of vaccination referred to in the above paragraph, complications following vaccination were seen in all of the specialities. The symptomatology in these specialities has been as variegated as are the symptoms and signs in postvaccinial encephalitis, and, as in post-vaccinial encephalitis, this variegation should be considered of importance. As in the ophthalmic complications, the important factor is the appearance of symptoms at a specific time interval, namely, seven to twelve days. Thus the appearance of complications elsewhere in the body after the same interval should be regarded with significance. If one only remembers that the patient has been vaccinated, and seven days later he blossoms forth with an ocular complication, then that ocular complication is a product of the vaccination. The nature of the ocular complication is of no importance, from the aetiological point of view. This same principle applies to diseases of other organs.

As mentioned previously, it has been shown that the pathological picture of post-vaccinial encephalitis and the encephalitis of the acute exanthamata are identical. Krieder ${ }^{15}$, in experiments and in autopsy studies in measles, has shown a perivascular lesion consisting of a thrombus formation, which explains the nature of the lesion. The participation of the central nervous system in uncomplicated measles is almost constant. The cerebral symptoms of measles, such as the changing uneasy capricious disposition, etc., are seldom considered neurologically. A meningo-encephalitic reaction is frequently seen, but these symptoms vanish very rapidly and are only lightly regarded. Wohlwill ${ }^{26}$ has uncovered many lesions of the central nervous system, although encephalitic symptoms were masked during the course of the measles pneumonia. These changes were found at autopsy studies on patients who died of measles pneumonia. It has also been shown that in many cases of post-vaccinial encephalitis the lungs showed bronchial pneumonia of a type similar to that of the measles pneumonia. Parker Heath ${ }^{14}$, in reporting upon a case of measles encephalitis, described an ophthalmoscopic picture resembling embolism of the central retinal artery. Because of the significance of this case I am repeating the report in some detail :- 
Clinical History.-J.P., a boy of Italian parentage, aged 6 years, had developed measles eleven days before admission. There was a rash, and then convalescence. Blindness developed on the eleventh day after the onset of measles.

Eye Examination.-Ophthalmoscopic examination showed in the right eye a distinct pallor of the nerve head, and a loss of capillary colour, without loss of substance. The most extraordinary picture was seen in the arteries, which were reduced to threads, and were carrying little or no blood. The veins were dark in colour, and reduced in calibre throughout, but relative to the arteries were engorged. The entire retina showed loss of transparency not associated with haemorrhage or exudation. The foveal reflex appeared a deep red, somewhat diffuse, through a more exaggerated overlying non-transparent retina. The left eye presented essentially the same picture. Appearances resembled bilateral embolism of the central arteries. On the seventh day the patient's eyes responded to light stimuli for a short interval. On the tenth day the child suddenly announced that he could see. The fundi showed more filling of the arteries.

Since the pathology of post-measles and post-vaccinial encephalitis have been shown to be identical, it may be assumed that the histopathological picture found in Von Herrenschwand's second case could possibly produce a variation of the fundus picture seen in Heath's case. Heath's patient revealed an eye condition which was bilateral, oedematous, transitory, reversible and in several other features characteristic of allergy. The fundus picture may have been modified by the pressure exerted by fluid in the tissue spaces. The arterial thinning was related to this extra-arterial pressure, whereas the intra-arterial pressure likewise was unusually low, since the systemic diastolic blood pressure was reported as $\mathbf{4 0}$ or less.

Heath, in his statement, "It is very unlikely that an opportunity will ever arise for an anatomical study of a similar case," probably would be very interested in the post mortem report of Von Herrenschwand's case number two. It appears that, although Heath does not claim an allergic basis for this case report, yet the stressing of localized oedema as the dominant sign points toward such a concept. Furthermore, it would appear that the acute retinal oedema and other vascular changes in the retina in Heath's case, and the retrobulbar picture in Von Herrenschwand's case may be similar in nature to the acute perivascular pathology of encephalitis, if we make proper anatomical allowances. The similarity of the ocular picture shown above lends more significance to many transitory ocular symptoms casually mentioned in measles encephalomyelitis. These symptoms should be considered more gravely since Ford ${ }^{10}$ has shown that recovery from measles encephalomyelitis is not nearly as complete as we have believed, and that sequels may arise several years later.

It is the purpose of this paper to show that ocular complications developing within a specific period after vaccination are part of a post-vaccinial ocular syndrome. That such a relationship may 
exist in other organs is also hinted at. It would seem, therefore, to be worth while to investigate the state of the host a little more intently before performing vaccination.

\title{
REPERENCES
}

1. ADLER, A: (1940) -Arch. Neïrol. arid Psychiat., 44, 541.

2. BENEDICT, WM. (1942).-Atch. of Ophthal., 28, 988.

3. BRICKNER and BRILI (1941).-Arch. Neurbl. and Psychiat., 46, 16.

4. CogAN; D. (1945).-Arch. of Ophthal., 23, 144,

5. Davidof F, L. H. (1932).-Jl. Exper. Med., 55, 163.

6. Ferraro, A. (1944).-Arch. Neutol. and Psychiat., 52, 413.

7. FINLEY, K. H. (1937).-Arch. Neurol. and Psychiat., 37, 505.

8. Flexner, S. (1930).-Ji. Amer. Med. Asśoc., 94, 305.

9. Fol. Is and RICH (1943).-Bull. Johns Hopkins Hosp., 66, 106-122

10. FORD, F. R. (1928.)-Bull Johns Hopkins Hosp., 43, 140.

11. FrAN RIIN and BRICRNER (1947).-Arch. Neurot. and Psychiat., 58, 2, 125.

12. GranzmanN, E. (1927).-Schweiz. Med. Wöch., 57, 145.

13. GREENFIELD, J. G. (1929) -Brain, 52, 171.

14. HEATH, P. (1932).-Amer. Jl. Ophthal., 130.

15. KRIEDER, cited by FERRARO, A. and SchafFer, J. H. (1931).-Arch. Neurol. and Psychiat., 25, 570.

16. MADer, A., cited by Scheyling (1939).-Klin. Monatsbl. f. Augenheilk., 52, 223.

17. Marsden, J. P. and HuRst, E. W. (1932).-Brain, 53, 145.

18. MCALPINE (1947). -Brain, 69, 233-35.

19. MORRIson (1947).-Arch. Neurol. and Psychiat., 58, 391.

20. NeAL. J. B. (1942).-Enceph. Clin. Study, Grune and Stratton, N.Y., 137-261.

21. Putnam, T. J. (1939).-Arch. Neurol. and Psychiat.. 41, 1089.

22. Rucker (1945). - Jl. Amer. Med. Assoc., 127, 97.

23. Spielmeyer, W.-Zeitschr. $f$. d. ges. Neurol. and Psychiat., 118, 1 , $1928 ; 142,159,1932 ; 99,756,1925$.

24. VoN HERRENSCHWAND (1939).-Klin. Monatsbl. f. Augenheilk., 102, 815-23.

25. VoGT (1925). - Ji. Psychiat. and Neurol., 31, 245.

26. WoHLWILl, F. (1931).-Zeitschr. f. d. ges. Neurol. and Psychiat.; $26,322$.

27. ZAPPERT, and KAISR, M. (1935).-Zeitschr. f. Path., 48, 474.

28. Zeligs (1947). -Psych. Med.. 9, 110.

29. Grinker, R. R. (1944).-Neurol. Third edition. Thomas, Springfield, Ill.

\section{THE TREATMENT OF HYPOPYON ULCER OF THE CORNEA}

BY

\author{
E. H. CAMERON \\ EDINBURGH
}

THE problem of the infected corneal ulcer in miners has for many years been a serious one in Edinburgh and has been a cause of considerable loss̀ of vision and working capacity. About forty thousand miners are employed in the Lothians and Fife, and the great majority of the eye injuries which occur among them are treated in the Eye Department of the Royal Infirmary. For 